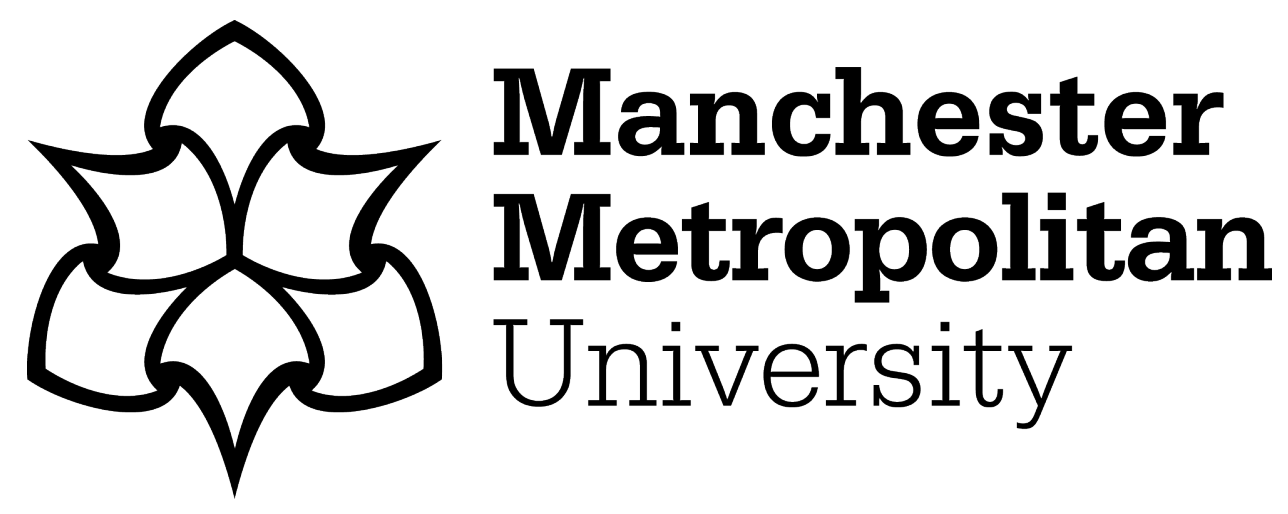

Wild, Benjamin Linley (2020) Critical reflections on cultural appropriation, race and the role of fancy dress costume. Critical Studies in Fashion \& Beauty, 11 (2). pp. 153-173. ISSN 2040-4417

Downloaded from: https://e-space.mmu.ac.uk/627736/

Version: Accepted Version

Publisher: Intellect

DOI: https://doi.org/10.1386/csfb_00014_1

Please cite the published version 


\title{
Critical reflections on cultural appropriation, race and the role of fancy dress costume
}

\begin{abstract}
Cultural appropriation in fashionable dress has become an increasingly urgent subject within scholarly and generalist discussions. Few weeks now pass without a news story criticizing a fashion brand for producing and promoting culturally insensitive clothing. A form of clothing most frequently and controversially associated with cultural trespass, but generally marginalized within academic enquiries, is fancy dress costume. This article seeks, first, to promote a critical and continuous academic engagement with fancy dress costume and contribute to a growing body of scholarship that recognizes its cultural and social importance. Second, I complicate discussions about the causes of cultural appropriation within fancy dress costume by reflecting on the circumstances and motives in which people perform, dressed very differently to their conventional appearance. Addressing these points, the article makes a unique contribution to clothing studies and discussions about cultural appropriation by advocating a more nuanced understanding of people's self-awareness when they participate in fancy dress costume, and suggests how this might be achieved.
\end{abstract}




\section{Introduction}

Cultural appropriation in fashionable dress has become the subject of increasingly widespread, even vociferous, discussion over the past ten years. Brands across the fashion industry, from H\&M to Gucci, have been called out for producing and promoting garments that appear to demean other cultures by reducing them to hackneyed and hurtful stereotypes (Scott 2016; Aldo 2018; Davidson 2019). The clothing most frequently and controversially associated with cultural appropriation is less conventional but equally prevalent - fancy dress costume. The term fancy dress costume is ambiguous and requires explanation. In my recent book, Carnival to Catwalk: Global Reflections on Fancy Dress Costume, I define fancy dress costume as'a performative form of dress, imaginative and incongruous, worn for a discrete occasion and limited time that disrupts the place of the individual within the social and political relationships of a specific community' (2020: 1). I have further argued that fancy dress costume is not unidimensional and that it exists on a continuum with different levels of complexity, from partywear to cosplay and bespoke commissions, and that it is shaped by different relations of power, akin to a conventional fashion spectrum that places haute couture and fast fashion at opposite ends (2019a: 18-20).

The definition of fancy dress costume that I propose is an attempt to strike a semantic and conceptual compromise, in three respects. First, while anglophone academics and curators in the United States and Northwest Europe use the term fancy dress, a generalist audience, particularly within the United States, may substitute the term costume because fancy dress can refer to a (man's) smart or formal appearance (Wild 2020: 2-3). Moreover, within the United Kingdom, partywear hire businesses increasingly describe their products as costume, and not fancy dress, which can be associated with the trivial and tawdry (Coulbault 2017). Second, anglophone words associated with dressing up are established in the vocabularies of former British colonies. Across West Africa, where traditions of dressing up remain prevalent, this usage includes the terms fancy dress, masquerade and mask, which have no equivalent in indigenous languages (Wild 2020: 50). Third, reappraisal of the concept of costume by academics, who demonstrate the various ways in which it is used performatively to articulate people's identities, supports analysis of the affect of fancy dress on wearers and spectators (Barbieri 2017; Boumaroun 2017; Hann 2017). Compromises are rarely perfect, and my decision to conjoin fancy dress and costume has implications. Linda Welters and Abby Lillethun suggest costume is a 'puzzling' term that poses problems for scholars because it is conventionally associated with national and ethnic dress (2018: 19). Consequently, it is freighted with uncomfortable associations of exoticism and colonialism (Kaiser 2012: 56). Nonetheless, the term fancy dress costume and its definition incorporate current terminologies and seek to embrace - equally - global iterations of this sartorial form. 
The term cultural appropriation is similarly equivocal. I follow Richard A. Rogers, who suggests cultural appropriation is 'the use of one culture's symbols, artifacts, genres, rituals, or technologies by members of another culture - regardless of intent, ethics, function, or outcome' (2006: 476). I further accept Rogers' four categories of appropriation - exchange, dominance, exploration and transculturation - which I elucidate below, and his assertion that 'cultural appropriation is inescapable' because it is 'intertwined with cultural politics' (2006: 474, 499).

The purpose of the article is twofold: first, to promote a more critical and continuous engagement with fancy dress costume and to contribute to a growing body of scholarship that recognizes its cultural and social importance (Rachamimov 2006; McQuillen 2013; Vaclavik 2019; Wild 2019a, 2019b); second, to complicate discussions about the causes of cultural appropriation within fancy dress costume by reflecting on the circumstances and motives in which people perform, dressed very differently from their conventional appearance. Addressing these points, the article makes a unique contribution to clothing studies by providing a nuanced interpretation of the reasons why cultural appropriation occurs through a series of reflections on the negotiations that transpire when people participate in fancy dress costume. For many scholars, including those cited below, this means study of people's self- and social identities as if they are 'either/or'. An approach informed by Black feminists and pursued here, which engages explicitly with the perpetual interweaving of people's quotidian and cultural experiences, and encourages a 'both/and' perspective, is more likely to be constructive in grappling with the complexity of this topic (Salami 2020: 11-14).

I approach this topic with two premises that have been established in my previous research. First, the identification of cultural appropriation within a person's fancy dress costume has the potential to be greatly revealing about the prevalent social attitudes and mores of their community. This is because the incongruity of fancy dress costume and its apparent abnegation of conventional modes of public behaviour implicitly demonstrate their ongoing relevance and necessity. Furthermore, the sartorial licence typically afforded to costumed participants means their clothing choices can reveal, or at least hint towards, an undercurrent of feelings that are otherwise difficult for analysts to gauge (Wild 2019b: 394-95; 2020: 5-6, 33-34, 55-56). Second, although fancy dress costume is typically conceived to be worn in public, consideration of the motivations and manner in which it is created, and how the act of costuming is performed, emphasizes the very complex nature of meaning-and message-making that the process of dressing as someone or something else involves. Akin to a prism that splits a ray of light into its constitutive colours, I contend that the study of fancy dress costume can elucidate, if not ever wholly clarify, the myriad internal and external considerations that shape public presentations of self. In the case of culturally problematic motifs that appear within a costume, their existence will be attributable to multiple factors. Consequently, whilst acts of cultural appropriation within fancy dress costume (and beyond) should continue to be called out where offence is caused, greater effort is required to understand why they occur, and why their occurrence has 
possibly increased over the last twenty years; they are certainly more intensely scrutinized through the news and social media.

The article is conceived in the spirit of analyses by Rogers, Minh-Ha T. Pham and James O.Young, which call for a more nuanced consideration of the causes and consequences of cultural appropriation (Rogers 2006; Pham 2014, 2017; Young 2010). More directly, my writing is prompted by empirical research that investigates self-identity and social identity, depersonalization and deindividuation (Abrams 1994; Mullen et al. 2003; White et al. 2017). One article that links many of these ideas was my spur. Authored by Jennifer C. Mueller, Danielle Dirks and Leslie Houts Picca,'Unmasking racism: Halloween costuming and engagement of the racial other' investigates the motivations and meanings of Halloween costuming among college undergraduates in the United States. The article was published in 2007, but its findings have not been widely discussed in connection with fancy dress costume.

Approaching this discussion as a historian, and mindful of the necessity and virtue of personal reflexivity in the research process that has long been advocated by feminist scholars, my method is that of humanistic critique (Ackerly and True 2008; Hesse-Bibber and Piatelli 2014). To use Edward Said's formulation, my aim is to 'introduce a longer sequence of thought and analysis' and, in so doing, 'to use one's mind historically and rationally for the purposes of reflective understanding and genuine disclosure' ([1978] 2003: xvii). The intention is to add shades of grey to a discussion largely shaped by empirical analysis, which tends to produce conclusions that are less expressive and reflective of people's myriad motivations and behaviours. A humanistic critique supplemented by empirical analysis might be better able to draw out some of these complications than either approach pursued separately.

\section{The cause and consistency of racial discrimination in fancy dress costume}

Since the start of the new millennium, problematic examples of cultural appropriation in people's dress and appearance have appeared to multiply. Few weeks now pass without a censorious news story condemning a fashion brand for promoting a form of dress that demeans another culture by reducing it to stereotypes, typically on the basis of race and ethnicity (Rivas 2018; Ferrier 2019; Asmelash 2020). Media discussions of cultural appropriation in dress are not unproblematic, and Pham writes of being 'tired of fashion criticism' because it reaffirms 'the very thing [it] intend[s] to oppose: White Western domination over and exploitation of culture at the expense of everyone else' (Pham 2014).

Whilst Pham's writing dwells on racial and ethnic trespasses that occur within fashionable dress, the 'reductive binaries' that she problematizes are particularly apparent in cases of cultural appropriation that involve fancy dress costume, especially in news headlines since 2000. For example, in 
September 2019, Canadian prime minister Justin Trudeau's re-election campaign was embroiled in controversy after a photograph emerged of him wearing blackface as a form of fancy dress costume in 2001. Two more photographs of Trudeau donning blackface as costume during his adolescence were subsequently reported (Kambhampaty et al. 2019; Fieldstadt and Radofsky 2019). Condemnation of Trudeau's indiscretion recalls the outcry that occurred when Britain's Prince Harry was photographed wearing a Nazi-style armband with a safari suit at a colonial and natives party in 2005 (Tweedle and Kallenbach 2005). Global reporting of these incidents drew attention to the racial insensitivity of the men's costumes and the apparent exposure of a latent racist belief in white privilege.

The criticism faced by the prime minister and prince regarding their fancy dress costume choices was commensurate with them each holding high public office. The negative reporting was also reflective of a belief, prevalent since at least the eighteenth century, that a person's choice of fancy dress costume (inadvertently) reveals deeper, often nefarious aspects of their character (Wild 2020: $3-4,9-10,17-21)$. In recent years, concerns about the apparent revelatory nature of dressing up has focused on the persistence of primarily white people's anxiety about race, even the existence of deeply held, and perhaps subconscious, racist views.

Research undertaken by Mueller, Dirks and Picca in the southern United States about the choice of Halloween costumes worn by American college undergraduates - the majority of whom were white, female and aged between 18 and 25 - gives credence to these misgivings. Analysing 663 of the students' written journals from the spring of 2002 to the autumn of 2003, with a supplementary survey in autumn 2004, Mueller, Dirks and Picca compared responses to the conception, creation and affect of costumes worn at different Halloween festivities (2007: 319-20). They conclude with the suggestion that

for many [people in the United States], Halloween has become a culturally tolerated, contemporary space for the racist 'ghost' to be let out of the box [...] Halloween's combination of social license, ritual costuming and social setting make the holiday a uniquely constructive context for negative engagement of racial concepts and identities.

The survey's findings, pursued further by Picca and Joe R. Feagin in Two-Faced Racism: Whites in the Backstage and Frontstage, albeit without reference to fancy dress costume, are compelling. Nevertheless, the suggestion that racially motivated cultural appropriation through Halloween costume exposes a fault-line peculiar to American society is problematic, given the existence of similar forms of racially influenced dress in other parts of the world - not least Trudeau's Canada and Prince Harry's Britain.

'Racial ghosts' do exist beyond the United States. In Britain, for example, Stuart Hall has suggested that the country's 'long imperial history' could have 'laid the trace of an active racism 
in British popular consciousness' ([1980] 1996: 52). Hall was writing in 1980, but recent examples substantiate his point. The 50th anniversary of London's Notting Hill Carnival, in August 2016, provided a moment to reflect on how an event inaugurated after the murder of Antiguan immigrant Kelso Cochrane in 1959 had become 'progressively less representative, both politically and culturally, of those who first created it [...] The carnival now primarily appears to cater for white British revellers - despite 44 per cent of London being black and minority ethnic (BAME) people' (Khalili-Tari 2016). However racism is understood - and Hall's 30-year-old assertion that we lack an 'adequate theory of racism' probably remains valid - it is apparent that the racist feelings Mueller, Dirks and Picca identify within the culture of the southern United States constitute a difference of degree rather than kind when they are compared, even casually, to other US regions and western countries (Hall [1980] 1996: 50). The prevalence of racial themes within American Halloween costumes may be pronounced because of the country's freighted history of race relations, but this is not the distinctive characteristic it may initially seem.

Moreover, American racial explorations through fancy dress costume are not always negative. In 2017, Black actors Sterling K. Brown and Chadwick Boseman, who star in Marvel Comic's Black Panther movie, spoke of their desire to see Black and white children appearing as the title character at Halloween. Brown remarked:

This Halloween, the first time I see a little kid, a white kid, dressed up as Black Panther, I'm taking a picture $[\ldots]$ because that's the crossover.

(Opam 2018)

Brown's sentiment is clearly borne of a desire to overcome racism in representation, and his hope for 'crossover' highlights the immaturity of the concept of post-race (Banet-Weiser et al. 2019). Nevertheless, his comment formed part of a broader, global dialogue about the appropriate presentation of, and response to, a Hollywood film that was unusual for having a leading cast of Black actors. Similar discussions had presaged the launch of Disney's Moana in 2017, an animated movie whose eponymous hero was a Polynesian princess from a fictional island called Motunui (Varathan 2017). Parents in the United States and Europe expressed concern about their perceived responsibility to marry costume revelry with racial respect when it came to satisfying children's enthusiasm to engage with the films and their characters.

The foregoing discussion suggests at least two implications for the conclusions reached by Mueller, Dirks and Picca. First, cultural toleration for a space in which to release the 'racist "ghost"' from the box appears to exist in multiple western countries. By inference, it could be suggested that these regions are haunted by a latent racism. Second, the observations made by the authors illuminate only some of the social and psychological motivations behind the creation and wearing of fancy dress costumes. 


\section{Fancy dress as cultural barometer}

If the role of fancy dress costume in the exploration of attitudes to race should be placed within a global frame, so should another strand of the argument made by Mueller, Dirks and Picca. The authors' assumption that the conception, creation and consumption of fancy dress costume can convey, even affirm, values that are socially prevalent but typically indeterminate - that tend to remain in the backstage, to use their phraseology - is substantiated by existing research. Through synchronic and diachronic surveys, scholars of medieval and early-modern Europe have convincingly shown that dressing up and the occasions when it was worn - chiefly carnival - bound communities together by highlighting shared values through dramatically performed non-verbal communication (Davis 1971; Kinser 1990: 3-16; Mänd 2005). Investigations are also beginning to elucidate the galvanizing role of fancy dress costume within the disparate communities and circumstances of later periods. Recent studies have included the nineteenth-century balls hosted by Britain's governors-general in Canada and the skits organized by fighting and incarcerated military personnel during and between the First and Second World Wars (Cooper 1997; Boxwell 2002; Rachamimov 2006; Wild 2020: 102-09). Whilst focusing on different chronologies and conditions, these studies show that events involving fancy dress costume facilitate the articulation of messages of social coherence because the incongruous appearance of participants effaces the badges and behaviour that conventionally delineate, and divide, social levels. Crucially, this research also shows that fancy dress performances typically achieve success in the demonstration of communal values by defining and disavowing opposites. The creation of otherness often involves participants engaging in cultural appropriation that demeans and ridicules members of their community who do not conform to socialized norms and behaviours.

For example, the balls of Canada's governors-general depicted historical periods of supposed barbarity before British rule to demonstrate the necessity of continued governance - political and social - from London (Cooper 1997: 132-33). The sailors and soldiers who wore fancy dress costumes during and between the World Wars often included allusions to castration and women. In so doing, they asserted their masculine identities by abnegating them (Wild 2020: 107). The creation of an 'other' through fancy dress costume is also a feature of contemporary dress-up events. For example, in an article about the role and meaning of costumed children on World Book Day, held on the first Thursday of every March in Britain, Kiera Vaclavik observes that the framing and resourcing of the event reinforces prevalent attitudes about gender and race because of a'severe lack of diversity and [the] predominance of male protagonists' (2019: 598). The event's lack of gendered and racial diversity affirms the cultural and social hegemony of white people and normative gendered roles.

The creation of an 'other' in public fancy dress events has an important implication for the study of Mueller, Dirks and Picca, specifically, and the discussion of cultural appropriation in fancy dress costume, generally, because it suggests that depictions of opposing beliefs and people are a relatively common occurrence in the western use of this sartorial form. Furthermore, the cited examples 
suggest that allusions to an opposite in fancy dress are not always, even chiefly, demonstrated with reference to race. For example, some of the more widely reported instances of cultural appropriation in contemporary British fancy dress appear to be influenced by the country's historic antipathy towards Germany. In September 2017, for example, a photograph emerged of British television presenter Paul Hollywood wearing a Nazi officer's uniform at a fancy dress costume party in 2003 (Booth 2017). In October 2018, to pre-empt costume-based misdemeanours, the University of Kent's Students'Union published a list of fancy dress costume subjects they wanted to ban, including depictions of Nazis, 'Chavs', political stereotypes akin to comedian Harry Enfield's 'Tory Boy', Mexican Sombreros and maracas. The rationale was to avoid the 'promot[ion of] an unsafe and exclusive campus' (MacSwan 2018; Bennett 2018). National newspapers followed suit by offering advice about suitable subjects for Halloween costumes. A list of topics to be avoided demonstrated an awareness of the potential for fancy dress costume to be racially charged. Readers were advised not to 'use someone else's culture as a costume' or to 'black up'. Non-racial forms of appropriation were also cited, including Anne Frank, trans people or those with mental illnesses (Gander 2018). Whilst these examples suggest that fancy dress themes are culturally contingent and reflect prevalent ideas within a community, they further show that the research of Mueller, Dirks and Picca presents degrees of difference between the United States' experience of costuming and that of other countries, rather than differences of kind.

\section{The meaning of fun in fancy dress costume}

Mueller, Dirks and Picca base their conclusions on a relatively small, and perhaps not overly indicative, student community. They acknowledge that 'our respondents reflect an oversampling and concomitant overrepresentation of data from the Southeast region of the U.S.' (Mueller et al. 2007: 331). Consequently, they seem to overemphasize the uniqueness of racist elements within American fancy dress costuming and minimize the existence of other forms of cultural appropriation within the sartorial form. The authors' focus on the United States also precludes recognition of the prevalent projection of an otherness through fancy dress costume across different cultures and chronologies. Their research nonetheless corroborates studies suggesting that fancy dress costume is a means by which salient, if largely subconscious and privately held, communal values can be shared. Their study is also important for considering the affect of costuming, a topic few academics have engaged with (Hann 2017).

Similar to the majority of studies that consider carnival and fancy dress costume, Mueller, Dirks and Picca defer to the work of Mikhail Bakhtin when considering the affect of dressing up. They suggest that the temporary suspension, even inversion, of people's quotidian roles creates a unique opportunity for communities to critically assess their strengths and weaknesses, to foster 
'societal renewal and regeneration' (Mueller et al. 2007: 317). The role of laughter in these ludic scenarios is particularly important. In a discussion on culture jamming -'activist multimedia productions and performances' (Parameswaran 2019: 59-60) - Radhika Parameswaran quotes directly from Bakhtin, who observes, '[1]aughter demolishes fear and piety before an object, before a world, making of it an object of familiar contact and thus clearing the ground for an absolutely free investigation of it' (Parameswaran 2019: 71). If laughter, perhaps specifically parody and irony, permits investigation, it also gives licence for people to communicate messages that might ordinarily be disavowed (2019: 71).

In studies of fancy dress, particularly, it has been suggested that the jocularity of costume facilitates group instrumentality. Laughter disarms, it blunts people's criticality and establishes a 'veneer of consensus' - to borrow a concept from Erving Goffman - that permits the effective exchange of otherwise challenging and resistible ideas (Goffman [1959] 1990: 21). Parting from Bakhtin, who considered this laughter ambivalent and subversive, subsequent academics and commentators tend to look upon it as benign (Bakhtin 1965: 11-18). It is the frequent references to laughter, of being carried away and seemingly forgetting oneself in accounts of costume participants, that encourage analysts to think that performances of dressing up lead to depersonalization, an increase in social awareness and reduction in self-identity. The sartorial form thereby reflects prevalent, if typically subconscious, cultural attitudes.

For example, in responding to questions about his decision to wear blackface when he was a teacher in his twenties, Justin Trudeau said he'should have known better' (Kambhampaty et al. 2019). He did not recall the incidents from his adolescence because he 'didn't understand how hurtful [his actions were] to people who live with discrimination every single day' (Fieldstadt and Radnofsky 2019). Similar exculpatory remarks are recorded in the research of Mueller, Dirks and Picca, who quote students claiming their costumes were'a harmless joke' and 'JUST THIS ONCE' (Mueller et al. 2007: 316, 320). Whilst these comments come from people who have worn and performed in fancy dress costume, a conundrum is that the experience of dressing up as described differs from the experience of dressing up as lived. Taken at face value, the remarks quoted above perpetuate a view that festive participants are 'often unreflective and unanalytical about what they are doing' (Bristol 1985: 27). The reality is more complex, even if participants are not cognizant of this.

In the presentation of their research, Mueller, Dirks and Picca discuss the legitimating fun of the costume performance, but do not dwell on remarks made by students about the making of their costumes, which evidences preparation and reflection. For example, they quote one student who 'asked [his] mom what she thought' (Mueller et al. 2007: 327); another student who was repeatedly pressed to contribute to a group costume performance (2007: 330); and still other students who wanted to ensure their costumed imitations were accurate (2007: 321-22). The authors also overlook the aftermath of a costumed event when, for example, decisions are made about the removal, 
retention or reuse of a fancy dress costume. From the personal experience of having to wait three days for grey eye shadow to comfortably fade after a costume portrayal, it is unlikely that decisions to wear make-up as part of a dressing-up performance will ever be taken wholly spontaneously, certainly after the first occasion, and particularly if it covers much of the face. The implication of this point is twofold. First, whilst the fun and laughter of costuming might facilitate the effective transmission of messages, they do not sufficiently explain people's often considerable engagement with dressing prior to and beyond this. Second, the use of laughter, irony and parody in a costume is the result of planning and creation prior to the public performance. Consequently, these ludic elements will likely be the result of an intentional desire to elicit a particular response from an audience when the costume is worn. If the idea of people being carried away or caught in the moment seems most credible only when they are dressed up and performing in a group setting, it would appear that decisions about costume choice and form owe more to factors that affect individuals primarily and groups secondarily. Correlatively, the explanation of cultural appropriation within costume perhaps needs to take more account of personal circumstances, regardless of the investigative challenges.

\section{Fancy dress costume and self-awareness}

Academics are increasingly aware of the affect of costume. Lauren Boumaroun has enunciated the concept of 'everyday cosplay', a specific form of fancy dress costume through which consumers 'appropriate the visual identity of fictional characters for their own self-expression through dress' (2017: 649). Hajo Adam and Adam Galinsky define 'enclothed cognition', which 'designate[s] the systematic influence of clothes on the wearer's psychological processes and behavioural tendencies' (2012: 918-19). Related to costuming, but not specifically mentioning it, Beverly Gordon has written about 'saturated experience' to refer to'self-contained, enchanted worlds, that [provide] heightened sensory awareness to increase the emotional, intellectual and social satisfaction [people derive] from undertaking routine domestic tasks' (2006: 1). Similarly, and again without specific reference to costuming but relevant to its study, Ramzi Fawaz refers to 'world making' as any instance 'when cultural products facilitate a space of public debate where dissenting voices can reshape the production and circulation of culture and, in turn, publicize counternarratives to dominant ideologies' (2016: 14).

To my knowledge, two empirical studies, beyond that of Mueller, Dirks and Picca, have analysed the affect of fancy dress costume on wearers. One study, involving children between the ages of 4 and 6 costumed as Batman, concluded that subjects' concentration spans increased because of deindividuation, a loss of self-awareness, social identity and accountability. Testing showed that children's self-awareness and social identity decreased as they completed tasks channelling the fictional hero's known fortitude (White et al. 2017: 1563-73). The findings from this experiment corroborate those 
of another, which investigated the impact on European American psychology students completing a three-page questionnaire whilst wearing a 'featureless, translucent mask' (Mullen et al. 2003: 107576). The study suggested that'a mask leads to a decrease in both self-awareness and social identity' (Mullen et al. 2003: 1077). It also implied that 'deindividuation does not spark a search for an increase in some form of identity' (Mullen et al. 2003: 1077).

The findings of these two experiments complicate the conclusions reached by Mueller, Dirks and Picca and perhaps highlight the problem of approaching self- and social identity as 'either/or'. The first challenges their findings by suggesting that a costume increases deindividuation. The second challenges the authors' assumption that social identity and depersonalization become salient among costumed wearers. Three caveats, at least, should be considered. First, the two experiments only look at the affect of a costume when it is worn. Second, participants were provided with costumes; they expressed no agency in their choice and had no attachment to them. Third, the controlled conditions of the experiments do not accurately reflect the ludic atmosphere of a festive occasion when such costumes are typically worn. In short, the experiments do not encompass the totality of a fancy dress costume experience, from conception through to creation and consumption. They privilege the public, and probably shortest, part within such episodes.

Qualitative studies that consider the totality of a fancy dress experience, from plan to performance, suggest that a person's self-identity is heightened during the conception and creation of a costume and continues to remain salient during its wearing and performance in public. This has important implications for discussions of cultural appropriation through dressing up because it implies that personal factors have a direct influence over such manifestations, along with prevailing cultural influences. Two examples from the international women's marches that occurred in 2017 clarify this point. First, Staten Island resident Vivian Vassar participated in a local march dressed as a suffragette (Wild 2020: 132). Her white outfit was assembled from various items of clothing that she already owned or had bought from high street stores and craft shops. Her costume is particularly striking for including a plain white sash. Vassar's choice was deliberate: 'I like to ask people what they think I should write on my sash. Because I've gotten so many interesting answers I decided to leave the sash blank' (Wild 2020: 132). This example shows that decisions about a costume's appearance are framed by a concurrent awareness of self-identity and social identity. Second, in Jakarta's women's march, Margianta Surahman Juhanda Dinata wore a custom-made Darth Vader body suit (Wild 2020: 135-36). He chose the costume because

I think [Vader] represents all of us, on how we can be bad but we can always redeem ourselves [...] For me, that is essentially the point of every social movement, to convince people that there is still good in the world.

(Wild 2020: 136) 
Wearing the costume involved Dinata concealing his conventional identity, but he claimed to feel 'empowered' by it, explaining that 'I even felt more myself than ever within the costume. Moreover, my experience on the March itself has brought more memorable meanings to my costume' (Wild 2020: 137). A strong self-identity was maintained when Dinata wore his costume publicly. His social identity was similarly heightened. These responses are typical from people who have spoken with researchers about the totality of their costume experiences. They challenge the self-categorization theory that suggests there is an inverse relationship between social identity and personal identity (Mullen et al. 2003: 1077). Studies of superhero costume and cosplay are particularly informative here, especially concerning issues of cultural appropriation (Brownie and Graydon 2016: 27-31, 61-68; Winge 2019: 33-34, 145-47).

If self-identity is salient when people conceive of, create or commission their fancy dress costumes, the manifestation of any culturally problematic aspects within their public appearance cannot be attributed to broader cultural factors - a pan-national 'racist "ghost"', for example - alone. Research that considers the totality of a costume experience suggests that decisions about dressing up and its intended affect do 'spark a search for an increase in some form of identity' (Mullen et al. 2003: 1077). Correlatively, the existence of motifs within a costume that may be considered culturally problematic will reflect the personal concerns of its wearer to a high degree. People in costume are never solely cultural avatars.

\section{Negotiating identities through fancy dress costume}

Popular fancy dress characters and themes demonstrate that this sartorial form is culturally contingent (Wild 2020: 22). The costumes people wear do reflect the prevalent social and political values of their communities, highlighting what is considered normative and non-normative, fashionable and trending. Nevertheless, the foregoing discussion, informed by Black feminist thought that sees individuals as 'interdependent' not 'independent' (Salama 2020: 85), has sought to complicate the relationship between costume and culture by suggesting that a fancy dress appearance and performance involves a negotiation - sometimes of a protracted nature - between a person's self-identity and social identity. The former seems to have a greater role in the conception, creation and commission of a costumed look; the latter has a greater role in the costumed performance, when there is an increased likelihood of depersonalization because of the sensation of being lost in the moment during the associated festivity.

Understanding the experience of fancy dress costume in this way demonstrates the important role of the sartorial form in the creation and conveyance of messages regarding personal identity. It is also useful for complicating discussions about cultural appropriation, which Rogers shows is not unidimensional. He argues that appropriation manifests itself in four categories: exchange, 
dominance, exploitation and transculturation (2006: 477). The first of his three terms explains different types of cultural exchange, from amicable to aggressive, by considering fluctuating degrees of '(in) voluntariness, (in)equality, (im)balance, and (im)purity' (2006: 499). The fourth category, transculturation, urges an understanding of culture as a'relational phenomenon that itself is constituted by acts of appropriation' (2006: 475). Rogers follows James Clifford in arguing that 'appropriations do not simply occur between cultures, constituting their relationships, but that such appropriative relations and intersections constitute the culture themselves' (2006: 492). This view aligns with the cultural authentication process, which explains how motifs from one culture are borrowed and adapted to occupy new meanings and roles in another culture (Erekosima and Eicher 2015: 350).

Neither Rogers' discussion of cultural exchange or Erekosima's and Eicher's discussion of the cultural authentication process make explicit reference to self-awareness and social identity, but their compatible models do facilitate an examination of the dynamic relationship between the individual and the group. In so doing, they make it possible to consider the liminal space that fancy dress costume creates for its wearers to contemplate and construct new formulations of self. Concurrent study of self and society - that is to say, acknowledgement of the affect of fancy dress costume on individuals within their communities - can stimulate more nuanced discussions about the causes and consequences of cultural appropriation and thereby eschew the dominance of 'reductive binaries', problematized by Pham, which look baldly at 'White Western domination over and exploitation of culture at the expense of everyone else' (Pham 2014).

\section{Myriad motivations: Reflecting on cultural appropriation through fancy dress \\ costume}

Fancy dress costume can be edifying, entertaining and escapist. It is a unique sartorial form that facilitates the exchange of abstract ideas that are inadequately conveyed through conventional discourse. The wearing and performance of fancy dress costume is socially contingent and will reflect prevalent, if sometimes subconscious, values of a community. Nevertheless, the conception and creation of a costumed appearance is primarily shaped by how a wearer imagines themselves being observed as they convey their personal motivations and beliefs publicly. This observation, derived from a combination of humanistic critique and empirical analysis, has implications for the investigation of cultural appropriation through fancy dress (and other forms of dress, generally). To focus on a person's public performance in costume may overestimate the salience of depersonalization and, therefore, imply that any manifestation of cultural appropriation is a partial, unreflective and uncritical regurgitation of their community's values. This argument privileges what is probably the shortest part of a costumed experience. It also entrenches reductive binaries as intellectual alchemy transforms different cultures into immutable monoliths that can be pitted against each other like conkers 
on string. This approach cannot effectively help to understand why instances of cultural appropriation occur around the world and appear to have increased since the new millennium, particularly within Europe and the United States.

A possible way forward presents itself if analysts consider the totality of a costumed experience, are cognizant of participants' self-identity alongside their social identity and view cultural appropriation as part of a ceaseless, dynamic and inevitable exchange between cultures. The complicated picture that emerges through this approach is more likely to yield robust explanations for the forms that cultural appropriation takes, the reasons why it occurs and to offer suggestions on why it might be occurring more frequently today.

If Rogers' dispassionate and dynamic framing of cultural appropriation is adopted, and if studies of fancy dress costume take greater account of individual motivations, it is possible to have a more expansive and interdisciplinary discussion about the nature of meaning- and message-making within this sartorial form. To consider one application, this approach might be useful to elucidate the 'killer clown craze' of 2016 that spread from the southern United States to Sweden within a few months. The viral transmission of the malevolent trickster was attributed by academics to people's feelings of unease, but it is interesting that this character should appear in Sweden when it is less engrained within the country's ludic traditions (Wild 2020: 22). This example of cultural exchange, which transcended regional cultures and appeared to share a common stimulus, may resonate with certain processes of fashion, notably fads, but it is not well explained by current approaches to cultural appropriation that assume people exist in homogeneous cultural groups. Disinclined to see different cultures as porous and interchanges between them without hegemonic motivation, many academics might even question if this is an example of cultural appropriation. The result is that the complex nature of meaning- and message-making within this episode is not fully understood. A more expansive approach to this example of cultural exchange might acknowledge Zygmunt Bauman's concept of liquid modernity - which explains the'self-propelling, self-intensifying, compulsive and obsessive "modernization" [of contemporary society], as a result of which, like liquid, none of the consecutive forms of social life is able to maintain its shape for long' (Bauman 2011: 11) - and suggest that people's use of another culture's symbols, even the shared use of cultural symbols by people around the world, can be a form of psychological salve.

Seeing cultural appropriation as part of an ongoing exchange between different peoples, and recognizing individual agency within this, can also facilitate the use of the cultural authentication process. For example, in Ghana, the bricolage construction of costumes for Winneba's annual fancy dress festival frequently sees symbols of western popular culture invested with new and very different meanings (Wild 2020: 51-53). Sometimes, meanings are entirely lost in translation. Symbols laden with connotation in the West, like satirical masks featuring politicians' faces, can be chosen simply because of how they look (Galembo 2016). The incorporation of western motifs into Ghanaian fancy 
dress is linked to the aesthetic concepts of 'fierce' and 'fancy' that were enunciated by western scholars in the nineteenth century. Fierceness is a belief that costumes are imbued with spiritual authority and should be respected by wearers and onlookers. Fancy is borne of prosaic motivations to demonstrate personal and family agency through creativity and resourcefulness (Nunley 1981: 54-55). This hybridity, which shows how self- and social identity jointly shape the creation and performance of West African fancy dress costume, defies a binary, and reductive, analysis. A more convincing explanation is offered by Hakeem Adam, who observes that'participants do not limit their imagination to the tradition that birthed their beloved festival, but look to themselves and their sociopolitical conditions that permeate society for inspiration for their costumes' (Adam 2018).

\section{Conclusion}

In contributing to discussions about cultural appropriation, it is perhaps easier to raise issues than refine them. Nonetheless, several remarks can be made by way of summary and with the hope of catalysing further discussion and study. First, the arguments of this article, prompted by the important research of Mueller, Dirks and Picca, urge analysts to consider cultural appropriation as part of an inevitable, ongoing exchange linked to people's negotiation of their self- and social identities, rather than an antagonistic tussle between 'outsiders' and 'insiders' (Young 2010: 5; Fiske 2000: 20-21). Second, the manifestation of cultural appropriation within fancy dress costume demonstrates the social importance of this sartorial form. As a conduit through which people can critically reflect upon their multifarious roles, because of the unique physical and psychological space that is created when people dress very differently to their conventional appearance, fancy dress costume is deserving of greater academic seriousness and study. Third, whilst the prevalence and popularity of fancy dress themes are culturally contingent, the selection of a costume is influenced considerably by personal factors. To understand acts of cultural appropriation within fancy dress costume, it is beneficial to adopt a Black feminist approach that considers people's self and social identity through a 'both/and' framework to acknowledge that individual agency does not occur within a vacuum, but is socially contingent. This means that people's performances in costume will be more readily seen as a negotiation between personal and prevailing cultural influences. It is not sufficient to attribute the existence of problematic themes within fancy dress costume (or any form of dress) to culturally prevalent ideas alone. Fourth, the study of fancy dress costume should seek to include the entirety of an individual's experience, from the conception and creation of their garment through to its wearing and after use. Presently, scholars tend to privilege the period of wearing a costume for analysis, but this is probably the shortest part of the costume experience. Fifth, and finally, reflective even discursive - analysis that integrates a humanistic critique with empirical research strategies, and where scholars are more aware of the position they occupy when conceiving, conducting and 
conveying their research, will likely elicit more nuanced, challenging and purposeful enquiries about the shifting nature and role of fancy dress costume and cultural appropriation, whether they are studied together or separately.

\section{References}

Abrams, Dominic (1994), 'Social self-regulation', Personality and Social Psychology Bulletin, 20:5, pp. 473-83.

Ackerly, Brooke and True, Jacqui (2008), 'Reflexivity in practice: Power and ethics in feminist research on international relations', International Studies Review, 10:4, pp. 694-99.

Adam, Hajo and Galinsky, Adam D. (2012), 'Enclothed cognition', Journal of Experimental Social Psychology, 48:4, pp. 918-25.

Adam, Hakeem (2018), 'Ghana's Winneba fancy dress festival is a living museum', OkayAfrica, 16 January, https://www.okayafrica.com/photos-winneba-fancy-dress-festival-living-museum. Accessed 14 March 2018.

Aldo, Edward (2018), 'The H\&M advert clearly didn't mean to be racist - which is worrying in itself', The Independent, 9 January, https://www.independent.co.uk/voices/hm-advert-racist-hoodiefashion-industry-retail-white-black-h-m-the-weeknd-a8149306.html. Accessed 11 April 2020.

Asmelash, Leah (2020), 'Comme des Garçons criticized for cultural appropriation for using lace front cornrow wigs', CNN, 19 January, https://edition.cnn.com/2020/01/18/us/comme-des-garconscornrow-wigs-trnd/index.html. Accessed 11 January 2020.

Bakhtin, Mikhail (1965), Rabelais and His World (trans. Hélène Iswolsky), Bloomington, IL and Indianapolis, IN: Indiana University Press.

Banet-Weiser, Sarah, Mukherjee, Roopali and Gray, Herman (2019), 'Postrace racial projects', in R. Mukherjee, S. Banet-Weiser and H. Gray (eds), Racism Postrace, Durham, NC: Duke University Press, pp. 1-22.

Barbieri, Donatella (2017), Costume in Performance: Materiality, Culture, and the Body, London: Bloomsbury.

Bauman, Zygmunt ([1988] 2011), Culture in a Liquid Modern World (trans. Lydia Bauman), Stockport: Polity Press.

Bennett, Rosemary (2018), 'Unforgiven: Now students ban cowboy outfits', The Times, 12 October, https://www.thetimes.co.uk/article/unforgiven-kent-university-students-have-banned-fancydress-cowboy-outfits-v9xtlscj8. Accessed 11 January 2020.

Booth, Robert (2017), 'Paul Hollywood pictured wearing fancy-dress Nazi uniform', The Guardian, 10 September, https://www.theguardian.com/lifeandstyle/2017/sep/10/ 
great-british-bake-off-presenter-paul-hollywood-pictured-wearing-fancy-dress-nazi-uniform. Accessed 3 November 2019.

Boumaroun, Lauren (2017), 'Becoming Annie: When film costume and fashion converge', Fashion Theory, 21:6, pp. 647-66.

Boxwell, David A. (2002), 'The follies of war: Cross-dressing and popular theatre on the British front lines, 1914-18', Modernism/Modernity, 9:9, pp. 1-20.

Bristol, Michael D. (1985), Carnival and Theater: Plebian Culture and the Structure of Authority in Renaissance England, New York: Methuen.

Brownie, Barbara and Graydon, Danny (2016), The Superhero Costume: Identity and Disguise in Fact and Fiction, London: Bloomsbury.

Castle, Terry (1986), Masquerade and Civilization: The Carnivalesque in Eighteenth-Century English Culture and Fiction, Stanford, CA: Stanford University Press.

Cooper, Cynthia (1997), Magnificent Entertainments: Fancy Dress Balls of Canada's Governors General 1876-1898, New Brunswick: Goose Lane Editions.

Coulbault, James (2017), personal communication with the marketing director of Angels Fancy Dress, London, December.

Davidson, Emma Elizabeth (2019), 'KKW just debuted a collection of shapewear named "Kimono" and Japanese people are not happy about it', Dazed, 26 June, https://www.dazeddigital.com/ fashion/article/45050/1/kim-kardashian-west-kimono-shapewear-controversy-japanese-cultural-appropriation. Accessed 12 April 2020.

Davis, Natalie Zemon (1971), 'The reasons of misrule: Youth groups and charivaris in sixteenthcentury France', Past \& Present, 50, February, pp. 410-75.

Erekosima, Tonye V. and Eicher, Joanne B. (2015), 'The aesthetics of men's dress of the Kalabari of Nigeria', in J. B. Eicher and S. L. Evenson (eds), The Visible Self: Global Perspectives on Dress, Culture and Society, 4th ed., London: Bloomsbury, pp. 349-61.

Fawaz, Ramzi (2016), The New Mutants: Superheroes and the Radical Imagination of American Comics, New York and London: New York University Press.

Ferrier, Morwenna (2019), 'Gucci withdraws $\$ 890$ jumper after blackface backlash', The Guardian, 7 February, www.theguardian.com/fashion/2019/feb/07/gucci-withdraws-jumper-blackface-balaclava. Accessed 7 November 2019.

Fieldstadt, Elisha and Radofsky, Caroline (2019), 'Justin Trudeau admits to wearing blackface after three instances emerge, won't rule out more', NBC News, 19 September, www.nbcnews.com/ news/world/third-instance-canadian-prime-minister-justin-trudeau-darkened-makeup-surfaces-n1056361. Accessed 9 October 2019.

Fiske, John (2000), Understanding Popular Culture, 2nd ed., London: Routledge.

Galembo, Phyllis (2106), Maske, New York: Aperture Foundation. 
Gander, Kashmira (2018), 'How not to dress like an offensive idiot on Halloween', The Independent, 11 October, http://www.theindependent.co.uk/life-style/halloween-costume-how-not-offensive-idiot-fancy-dress-racism-aa8005291.html. Accessed 12 October 2018.

Goffman, Erving ([1959] 1990), The Presentation of Self in Everyday Life, London: Penguin Books.

Gordon, Beverly (2006), The Saturated World: Aesthetic Meanings, Intimate Objects, Women's Lives, 1840-1940, Knoxville, TN: University of Tennessee Press.

Hall, Stuart ([1980] 1996), 'Race, articulation, and societies structured in dominance', in H. A. Baker Jr, M. Diawara and R. H. Lindeborg (eds), Black British Cultural Studies: A Reader, Chicago, IL: University of Chicago Press, pp. 16-60.

Hann, Rachel (2017), 'Debating critical costume: Negotiating ideologies of appearance, performance and disciplinarity', Studies in Theatre and Performance, 37:2, pp. 1-17.

Hesse-Bibber, Sharlene Nagy and Piatelli, Deborah (2014), 'The feminist practice of holistic reflexivity', in S. N. Hesse-Bibber (ed.), The Handbook of Feminist Research: Theory and Praxis, Thousand Oaks, CA: Sage Publications, pp. 557-82.

Kaiser, Susan B. (2012), Fashion and Cultural Studies, London: Bloomsbury.

Kambhampaty, Anna Purna, Carlise, Madeline and Chan, Melissa (2019), 'Justin Trudeau wore brownface at 2001"Arabian Nights" party while he taught at a private school', Time, 18 September, https://time.com/5680759/justin-trudeau-brownface-photo/. Accessed 5 October 2019.

Khalili-Tari, Daniel (2016), 'Black culture is popular, but everyone should remember why Carnival started when partying this weekend', The Independent, 28 August, www.theindependent.co.uk/ voices/notting-hill-carnival-racism-dont-forget-why-it-started-a7210986.html. Accessed 6 September 2016.

Kinser, Samuel (1990), Carnival American Style: Mardi Gras at New Orleans and Mobile, Chicago: University of Chicago Press.

Klein, Alyssa Vingan (2019), 'Internal memo from Gucci CEO shows he's taking the blackface scandal very seriously', Fashionista, 11 February, https:/fashionista.com/2019/02/gucci-blackfacesweater-ceo-marco-bizzarri-statement. Accessed 7 November 2019.

MacSwan, Anna (2018), 'Costume ban by Kent Union will make university “a laughing stock" claims students', KentOnline, 19 October, https://www.kentonline.co.uk/canterbury/news/costumeban-makes-uni-a-laughing-stock-claim-students-191862/. Accessed 23 March 2020.

Mänd, Anu (2005), Urban Carnival: Festive Culture in the Hanseatic Cities of the Eastern Baltic, 13501550, Turnhout: Brepols.

Marshik, Celia (2017), At the Mercy of Their Clothes: Modernism, the Middlebrow, and British Garment Culture, New York: Columbia University Press.

McQuillen, Colleen (2013), The Modernist Masquerade: Stylizing Life, Literature and Costumes in Russia, Madison, WI: University of Wisconsin Press. 
Mueller, Jennifer C., Dirks, Jennifer C. and Picca, Leslie Houts (2007), 'Unmasking racism', Qualitative Sociology, 30:April, pp. 315-35.

Mullen, Brian, Migdal, Michael J. and Rozell, Drew (2003), 'Self-awareness, deinviduation, and social identity: unravelling theoretical paradoxes by filling empirical lacunae', Personality and Social Psychology Bulletin, 29:9, pp. 1071-81.

Nunley, John (1981), 'The fancy and the fierce', African Arts, 14:2, pp. 52-58, 87-88.

Opam, Kwame (2018), 'The many meanings of Black Panther's mask', New York Times, 13 February, https://www.nytimes.com/2018/02/13/style/black-panther-children-costumes.html. Accessed 7 February 2018.

Parameswaran, Radhika (2019), 'Jamming the color line: Comedy, carnival, and contestations of commodity colorism', in R. Mukherjee, S. Banet-Weiser and H. Gray (eds), Racism Postrace, Durham, NC: Duke University Press, pp. 57-71

Patel, Arti (2019), 'Gucci apologizes after "blackface" sweater causes backlash', Global News, 7 February, https://globalnews.ca/news/4934147/gucci-blackface-sweater/. Accessed 6 November 2019.

Pham, Minh-Ha T. (2014), 'Fashion's cultural-appropriation debate: Pointless', The Atlantic, 15 May, https://www.theatlantic.com/entertainment/archive/2014/05/cultural-appropriation-in-fashionstop-talking-about-it/370826. Accessed 6 November 2019.

Pham, Mina-Ha T. (2017), 'Racial plagiarism and fashion', QED, 4:3, pp. 67-80.

Picca, Leslie Houts and Feagin, Joe R. (2007), Two-Faced Racism: Whites in the Backstage and Frontstage, New York: Routledge.

Rachamimov, Alon (2006), 'The disruptive comforts of drag: (Trans)gender performances among prisoners of war in Russia, 1914-1920', American Historical Review, 111:2, pp. 362-82.

Rivas, Mekita (2018), 'Jennifer Lawrence's new Dior ad is being accused of cultural appropriation', Teen Vogue, 16 November, https://www.teenvogue.com/story/jennifer-lawrence-dior-ad-accusedof-cultural-appropriation. Accessed 8 November 2019.

Rogers, Richard A. (2006), 'From cultural exchange to transculturation: A review and reconceptualization of cultural appropriation', Communication Theory, 16:4, pp. 474-503.

Said, Edward W. ([1978] 2003), 'Preface (2003)', in Orientalism, London: Penguin, p, xvii.

Salami, Minna (2020), Sensuous Knowledge: A Black Feminist Approach for Everyone, London: Zed Books.

Scott, Kellie (2016), 'AussieBum chief reacts to claims Australia Day undies are offensive to indigenous cultures', ABC News, 14 January, https://www.abc.net.au/news/2016-01-14/aussiebum-ceoreacts-to-claims-australia-day-undies-offensive/7089772. Accessed 12 April 2020. 
Tweedle, Neil and Kallenbach, Michael (2005), 'Prince Harry faces outcry at Nazi outfit', The Telegraph, 14 January, https://www.telegraph.co.uk/news/uknews/1481148/Prince-Harry-faces-outcry-atNazi-outfit.html. Accessed 14 August 2018.

Vaclavik, Kiera (2019), 'World Book Day and its discontents: The cultural politics of book-based fancy dress', Journal of Popular Culture, 52:3, pp. 582-605.

Valinsky, Jordan (2019), 'Gucci hires diversity chief after blackface scandal', CNN Business, 30 July, https://edition.cnn.com/2019/07/30/business/gucci-diversity-officer-blackface-scandal/index. html. Accessed 9 November 2019.

Varathan, Preeti (2017), 'Please don't tell your kids they can't dress as Moana this Halloween', Quartz, 26 October, https://qz.com/1110802/moana-halloween-costume-please-dont-tell-your-kidsthey-cant-dress-as-moana-this-halloween/. Accessed 8 January 2020.

Welters, Linda and Lillethun, Abby (2018), Fashion History: A Global View, London: Bloomsbury.

White, Rachel E., Prager, Emily O., Schafer, Catherine, Kross, Ethan, Duckworth Angela L. and Carlson, Stephanie M. (2017), 'The "Batman effect": Improving perseverance in young children', Child Development, 88:5, pp. 1563-71.

Wild, Benjamin Linley (2019a), 'We need to talk about fancy dress: Connections (and complications) between the catwalk and fancy dress costume', Fashion Theory, https://doi.org/10.1080/13627 04X.2019.1686827.

Wild, Benjamin Linley (2019b), 'Clothing royal bodies: Changing attitudes to royal dress and appearance from the Middle Ages to modernity', in E. Woodacre, L. H. S. Dean, C. Jones, Z. Rohr and R. Martin (eds), The Routledge History of Monarchy, London: Routledge, pp. 390-408.

Wild, Benjamin Linley (2020), Carnival to Catwalk: Global Reflections on Fancy Dress Costume, London: Bloomsbury.

Williams, Robert (2019), 'Gucci pulls sweater slammed for resembling blackface imagery', Business of Fashion, 7 February, https://www.businessoffashion.com/articles/news-analysis/gucci-pullssweater-slammed-for-resembling-blackface-imagery. Accessed 10 November 2019.

Winge, Therèsa M. (2019), Costuming Cosplay: Dressing the Imagination, London: Bloomsbury.

Young, James O. (2010), Cultural Appropriation and the Arts, Chichester: Wiley-Blackwell.

\section{Suggested citation}

Wild, Benjamin Linley (2020), 'Critical reflections on cultural appropriation, race and the role of fancy dress costume', Critical Studies in Fashion \& Beauty, 11:2, pp. 153-173, doi: https://doi.org/10.1386/ csfb_00014_1 


\section{Contributor details}

Benjamin Linley Wild is senior lecturer in contextual studies (fashion) at The Manchester Fashion Institute, Manchester Metropolitan University. A cultural historian, Wild's work explores, broadly, the nature and role of meaning-making in people's dress and appearance. His recent work has focused on fancy dress costume, cultural appropriation and the self- and group presentation of people marginalized within their communities. His third book, Carnival to Catwalk: Global Reflections of Fancy Dress Costume, was published by Bloomsbury. He is currently under contract (to Bloomsbury) for Wearing Culture: Controversy, Negotiation and the Pursuit of Fashion.

Contact: Manchester Fashion Institute, Manchester Metropolitan University, Cavendish Street, Manchester M15 6BG, UK.

E-mail: b.wild@mmu.ac.uk

(1) https://orcid.org/0000-0001-7206-778X

Benjamin Linley Wild has asserted their right under the Copyright, Designs and Patents Act, 1988, to be identified as the author of this work in the format that was submitted to Intellect Ltd. 